\title{
Social capital as a predictor of delinquency in adolescent boys
}

\author{
Leila Fathi \\ Faculty member of Payame Noor University, Nazarabad Center, Iran \\ E-mail address: leilafathi89@gmail.com
}

\begin{abstract}
This study aims to investigate the relationship between social capital and delinquency in adolescents. This research has been conducted using a survey. In this research, 400 adolescent boys in Tehran were selected as samples based on the Cochran formula. Data were collected using researcher built- questionnaires. The results showed that with enhancement of social capital, levels of delinquency in adolescent boys decrease. And also by increasing the dimensions of social capital including social participation, social confidence, social support, social solidarity and interrelationships with others the delinquency in adolescent boys decreases and these relationships was statistically significant $(p<0.001)$. The results of multivariable regression also showed that dimensions of social participation, social confidence, social support, and social solidarity were as predictors of delinquency in adolescent boys $(\mathrm{p}<0.001)$ and by increasing them the levels of delinquency in adolescent boys decreased.
\end{abstract}

Keywords: Social capital; Delinquency; Adolescent; Social confidence; Social participation

\section{INTRODUCTION}

Social norms in the history of mankind, has always been subjected to change and in societies that have experienced industrialization and economical modernization, changes in social norms have increased in parallel with the above trend. Iran in recent years for various reasons has observed changes in social norms.

As destroying informal norms has caused loss of importance of life and all the affairs and activities have become monotonic and satisfaction with life has decreased. On the other hand, alternative institutions for producing this norms and social interactions have not been created in new conditions of society.

This factor has caused some social consequences including increased crime, poverty, delinquency, and generally various social harms in the society and has created a critical situation for the community (Shareapour, 2001). Status of violent behaviors in Iran in recent years has encountered the experts of social issues with an alarming situation.

For example, during the years 1997 to 2002, statistics of violence including murder, maim, and the destruction have been increased from 330,356 cases in 1997 to 535,469 cases in 2002 and it has had an annual average growth of about 12 percent.

Available evidences suggest a growing trend of violence from 544 cases in a population of 100 thousands in 1997 to 816 cases per 100 thousand populations in 2002 which shows a negative trend (Mousavi et al., 2007). Available evidences suggest that in fact during the recent decades, severe erosion of available social capital for adolescents and young people, 
both within the family and outside has been happened. In family, growth of ((human capital)) has been increased so that education is constantly increasing. But along with the growth of human capital, social capital that its prominent indicator is the presence of adults in the house and the conversation about the social, cultural, scientific, economic and political issues between parents and children has been fallen. In the community, the amount of erosion and the destruction of social capital are much higher.

As it seems an increase in crime rates in recent years has been due to the weakening of group relations between individuals and it have created many problems for the society. In addition, community has highly been exposure to individualism attacks in which individual interests have been prioritized over collective interests (Shareapour, 2001). Amount of social capital that we invest in our communities helps to maintain social order namely to prevent delinquency.

The main task in preventing delinquency is that future potential criminals become good citizens. If they become criminals behind bars of prisons, the annual cost for the society is enormous. This cost without financial and emotional costs is for the society during their sentence and after release (Mousavi et al., 2007).

The discussion of social capital in Iran can create new perspectives for us by correcting our attitude with respect to development issues. So that it results in which we do not look to development one dimensionally, but we consider it also in various aspects, especially in terms of positive social capital in the community. And we make sure that a change in social capital is an indicator of symptoms or public health and communities in which social capital is reduced for any reason, ruptures and a profound gap among the social groups emerge and it causes social buffers including formal and informal networks of organizations and social norms related to labor force participation and access to education do not function properly and the community encounters with various crises (Mobaraki, 2005).

This study aims to investigate the relationship between social capital and delinquency in Adolescent boys in Tehran.

\section{RESEARCH BACKGROUND}

Wright et al. (2001) examined the relationship between social capital of family and delinquent behaviors. Their initial data have been extracted from the National Youth Survey (NYS). Age of respondents is 11 to 24 years. According to Coleman's theory, their findings suggest that family social capital reduces delinquency rates over time and moderates the effects of mistreating.

Also, parental effort in terms of time spent and the amount of their attention decrease the probability of commitment of delinquent behaviors and socialization by delinquent peers. They also showed that the family social capital increases the interaction and the level of duties and provides a basis for social and informal control. Salmi and Kivivuori (2006) in his article entitled ((correlation between social capital and youth crime (the role of individual and structural indices) investigated the relationship between these two variables by controlling the individual and structural level indices of social capital. This study has been conducted in a sample of 5142 juveniles aged 15-16.

The results of regression analysis show that when the individual and structural level variables (e.g., self-controlling) are controlled, low control by the teacher and low interpersonal confidence are associated with criminal behavior. Controlling by parents, support by teachers and intergenerational linking with delinquency, are only correlated in two variables-models. It seems weak connections of parents that causes juveniles go to part-time jobs do not protect him against the risk of delinquency. 
Ozden Ozbay in his research entitled ((The relationship between social capital, defrauding, consumption of alcohol, and the use of violence)) studied 450 of university students in Turkey. Complete measures of social capital in this study include social capital of parents (such as membership in organizations, political participation, reading of book or newspaper, parental controls on social network of teens, and religion) and social capital of adolescents (such as social incapability, religion, relation with diffusion, social exchange among classmates, membership in organizations, confidence and voting).

The results showed that the most of measures of social capital are not significant and positive constant. And social capital has both positive aspects and negative aspects. Deprivation with a lack of social capital as a new concept was used for the first time. This concept had a positive impact on deviant behavior (Ozden Ozbay, 2008).

Aliverdinia et al. (2007) in a study investigated the relationship between family social capital and delinquency of adolescent boys and girls empirically using the Coleman family social capital theory and the theory of Hirschi's social bond. To investigate the mentioned relationship, a sample of 410 third year high school students in Sanandaj who were educating in 2007-2008 as been used.

The findings suggest that cognitive social capital within the family has had the highest explanatory power of delinquency among boy respondents. While structural social capital within the family has shown the maximum explanatory power of delinquency among girl respondents. Intimacy among family members and social support also have had a significant relationship with delinquency in boys among the components of family social capital, whereas among girl respondents, parental awareness and membership in social organizations have shown a significant relationship with delinquent behaviors (Aliverdinia et al, 2007).

\section{THEORETICAL BASICS OF RESEARCH}

\section{1. Social capital}

Social capital is a public resource that can have a tangible and non-tangible form. When the term "capital" is also applied in the other capital areas, it represents something that retains its identity even after repeated use, a thing that we can use it repeatedly, destroy it, obtain it or improve it. In general, the term social capital was first applied in 1916 in an article written by someone named Hani Fan who served in Education and Training of Virginia, US. He knew social capital includes assets that are mainly considered in the daily lives of persons, like sense of understanding, friendship, sense of sympathy, and social relationships among the individuals and families who make a social unit (Sharifian Sani, 2001; quoted by Feldman and Esaf, 1999).

Again in 1961 after a delay of half a century, Jane Jacob applied it in his classic work, "The Death and Life of Great American Cities", where he had explained in it that the compressed social networks in old suburban and mixed urban areas form a sort of social capital and in relation to maintaining cleanliness, absence of street crime and other decisions about improving quality of life, compared to the formal institutional factors such as police protection force and police force show more responsibility (Fokoyama, 2000).

Following him in 1970, Glenn Loury, an economist, and Ivan Light, a sociologist, used term "social capital" to describe the problem of intra-city economic development. In the 1980s, this term was used in a wider sense by James Coleman, a sociologist, and Robert Putnam, a political scientist, is also raised a strong and interesting debate about the role of social capital and civil society, both in Italy and in the United States. Interestingly, political scientists in Italy and in the America paid attention to Putnam's work; Coleman's original work was largely ignored. 
But Bollen and Onyx believe that Bourdieu and Coleman in the 1980s were first applied this term. Broad argumentations of social capital have increased after the publication of Putnam's works, especially after 1993. Therefore, sociologists like Pierre Bourdieu 1979 in the field of Marxist theory, Coleman 1988 in the field of individualism methodology used this concept and finally, it should be said that Putnam in 1993 transferred the contemporary use of social capital to economic realm practically (MollaMohseni, 2002).

Social capital can be classified in three social science approach: Pierre Bourdieu emphasizes the strategies to maintain or change the position of people in the socio-historical structures. James Coleman finds economic rationality and human capital and Robert Putnam involves a strong relationship with the civil liability. Fukuyama who used this term in the economic realm must also be added to this collection. From quantitative view point, social capital is a quantity; i.e. the more participation in the community and the larger number of voluntary associations, in other words, NGOs the higher social capital. Quantify has two different aspects including number of voluntary organizations in the community and number of members in each of these groups. Also the relationships of people with family members, friends and acquaintances, and generally with others include the quantitative aspect of social capital (Mobaraki, 2005).

From qualitative aspect should also be noted that social capital has an important qualitative dimension. To estimate social capital of the society it is necessary to consider the correlation and the degree of inter-group solidarity, mutual trust between actors, positive emotions and totally mental aspect. Quality has two dimensions. One dimension is an intergroup solidarity and the other one is solidarity among groups or the solidarity among groups existed in society. If in a community trust and solidarity within groups is high, but the solidarity is low among different groups or there is no coherence among them, this process will have negative effects for entire society and in fact, available social capital will be of a negative kind (Mobaraki, 2005).

\section{2. Delinquency}

From the perspective of the sociology, interpretation of deviant behaviors is in terms of social or cultural forces that are beyond the individuals. And because it originates from the classes and social structures, it affects on large groups of people. Thus the basic feature of this attitude toward delinquency is its social and ultra-individual nature. This means that the variables existed in the definition of delinquency are related to the concept of society, social structures and comprehensive social institutions. So not only it can be studied in a format restricted to a person or specific persons, but also accurate and correct understanding of it will be possible in a macro analytical form by understanding of these structures and institutions.

Due to expedience of the issue and its importance, we will mention four major theorists in this field:

1) Durkheim: Durkheim demonstrates collective nature of delinquency in the aspects as follow:

- Violation of the collective feelings: he knows the delinquency as a violation of axioms existed in ethnic sentiments and the collective conscience of society and he knows that it has cultural nature by emphasizing the point that the norms of any community rely on the foundation of the collective feelings.

- Mastery of personal demands at the time of mass authority: cases such as the collapse of social order are formed from Durkheim image of this collective nature. Then the weakness of mass authority and decay of community authority on the individual demands results in getting these demands out of society control. 
- He considers the delinquency as a natural phenomenon in social life (Salimi and Davari, 2008).

2) Merton: Selecting conformism of a person at the time of the inefficiency of public instructions. Merten applies following elements on the expression of this image:

- Gap and conflict between goals and means with social acceptance for some people that cause they imagine the inefficiency of collective behavior guidelines. And it ultimately leads to their weakness of adherence to those guidelines.

- Inner need of people to achieve those goals and means, and therefore forming conflicting needs in them.

- Psychological pressures to meet the needs that force the people to satisfy it by resorting to the specific options that can be called a more desirable option (or more accessible) among possible logical combinations for getting those two elements.

In this way he uses two kinds of variable including collective variables (pressure and anomie) and individual ones (choice of conformity) to draw the concept of delinquency.

3) Parsons: Learning correlation, voluntary and inconsistent with the community. Parsons in a sense as same as these two scholars defines delinquency as a phenomenon caused by a lack of organization; and claims that this situation sweeps the possibility of complete correlation of all components of a system away as well as its general and comprehensive motion; And it forces some of these components into a (partial correlation) with a weakened social order; Moreover, considering his explanation of delinquency, it will be revealed that he knows behaviors of people as a product of cultural Inductions in society and simultaneous socialization trainings resulted from individual selections and personal analyses from cultural lessons (Versley, 1999).

4) Albert Cohen: Alternative reaction versus the norms. Albert Cohen in similar expressions and followed a discussion about delinquency relativity applies the above-mentioned concept for explaining the nature of this phenomenon. At first, he reminds that not only different norms belong to different subcultures can be seen in society but also various patterns often against the behavior can be formed. That even methods of consistency with a normative rule could fundamentally be different ways with each other. In this way he considers calling the behaviors consistent with patterns of subculture as the delinquency as a kind of failure in society in recognizing the methods by which people adapt themselves with normative rules (Resheh, 1988).

5) Walter Miller: Behavior consistent with cultural patterns. Walter Miller in the (focal interests) theory considers deviations of delinquent juveniles as a behavior that gang culture knows it as the most appropriate option. Unlike Cohen, he believes that these people commit their deviant behaviors due to adhering to these collective traditions (Salimi and Davari, 2008).

\section{3. Theoretical framework}

Since the nature of this study is close to social structure and processes theories, we have tried in this study to investigate this relationship by emphasizing these theories. In these theories, it has been tried through various methods to use the concept of social capital or one of its reagents for explaining different capabilities of human communities with respect to solving wide domain of collective issues such as delinquency. One of branches of social structure perspective is pressure theory that anomie theory and social disorganization theory are two of the most important its subsets. These two branches are independent but they exist in accordance with each other inside the social structure perspective. According to social 
disorganization theory, social capital is the basis of social control because it creates outer collective force for imposing discipline.

What that enables groups with respect to impose norms and consequently with respect to increase their informal control level. Therefore, unorganized communities involve in delinquency and the other negative situations because they are not capable to accumulate necessary social capital (Rezo Claire, 1998). Initial concepts of abnormality pattern in explaining delinquency can mainly be observed in Durkheim's ideas and opinions in the field of need to protect from ethical links among people in the society. The main Durkheim in this filed was that life without ethical requirements or social necessities becomes unsustainable and finally results in formation of anomie phenomenon, namely abnormality sense that it is often as a preliminary for commitment of delinquency by people (Mobaraki, 2005). Anomie theory predicts that social confidence and delinquency will be decreased and increased, respectively in environments in where people have lower ethical discipline and behave highhandedly and tend to exploit others (abnormal environments) (Liederman, 1999). Social capital can affect delinquency rate of people and society through the other mechanisms and can decrease or increase it.

These mechanisms can be searched in socio-psychological processes and common interactions with people in all parts of social structure. These theories emphasize on people interactions with different organizations, institutions and social processes and argue that most people are affected by their family relationships, group links among peers, training experiences, and interaction with authoritative characters such as teachers, employers, and agents of justice system. If these relationships be positive and incentive, people can manage rules of society. But if these relationships be inefficient and destructive, common successes possibly become impossible and criminal solutions will be a proper alternative (Siegel, 2001). One of the theorists in this field is Edwin Sutherland that has emphasized on the role of social interaction in forming the behavior and attitudes of humans. By adding the concept of social capital to differential association theory, it can be concluded that by entering people in deviant groups and making close relationship with their members, values and delinquency norms are learnt over time and inasmuch as inter-group solidarity is high in them, hence people try to apply learnt deviant behaviors against the other groups to conserve their membership and team correlation in group.

It can be said in this state that a kind of social capital that exists among group members is of a negative kind of intra-group social capital and the more perverse social capital in the society, the more delinquency in the society (Mobaraki, 2005). Sutherland theory is one of the strongest theories in the field of creation of deviances that has large determining power up to now. Sutherland in his theory believed that deviances are generally learnt in form of initial groups such as friends and family. These groups are more effective than agents and formal authorities such as teachers, priests, and policemen or mass media like movies and newspapers (Rafeapour, 1999). One of the most important experts is Travis Hirschi that has beautifully demonstrated relationship between social capital and delinquency in his theory named "social control theory".

He considers link between the person and society as an important element in social control and believes that if this relationship be weak, the person feels lower pressure for conformity. But if this relationship be strong, the person will lose many things if he/she commits a delinquency, so he/she is forced to conformity (Mobaraki, 2005). Hirschi's pattern that is often known as "association theory", explains that creation of delinquency is caused by weakness in correlation among groups and social institutions and also weakening believes and faiths in society (Salimi and Davari, 2001). The result that Hirschi concludes from his own analysis is that society or a group with a strong mutual dependence is capable to control its members better than the other society or group if its members do not have strong dependence 
to each other. For example, he believes that whatever correlation among youths, parents, adults, and peers be large, youths become more interested in school and other acceptable social activities and whatever they accept believes and ideologies common in social environment and believe in them much more, lower probability will be existed to become deviant. In this specificity, Hirschi introduces four elements of attachment, commitment, involvement, and belief as elements linking the people to each other and society, in other words four behavior control variables.

\section{HYPOTHESES OF RESEARCH}

\section{a) Main hypothesis}

Delinquency of Tehran juvenile boys decreases with enhancement of social capital.

\section{b) Secondary hypotheses}

1- Delinquency of Tehran juvenile boys decreases with enhancement of social participation.

2- Delinquency of Tehran juvenile boys decreases with enhancement of social solidarity.

3- Delinquency of Tehran juvenile boys decreases with enhancement of social confidence.

4- Delinquency of Tehran juvenile boys decreases with enhancement of social interactions with others.

5- Delinquency of Tehran juvenile boys decreases with enhancement of social support.

\section{RESEARCH METHOD}

This research is of a kind of analytical-descriptive study that is often known as various titles such as survey studies, segment study, and filed study. This study is also of a kind of intensive studies from research depth point of view that separates it from intensive studies such as participation observation, phenomenological research and so on. Extensive studies aim to generalize results of a small indicator sample from community to entire population. In particular, this study is of a correlation kind that independent and dependent variables are not clear in it and in this reason they are called predictor variable and response variable.

\section{1. Statistical population and sampling method}

Statistical population of current study includes of Tehran juvenile students. Cochran's sampling formula was used to estimate the volume of statistical sample and 400 persons were used as the sample. Sampling of juvenile boys was done using random cluster method. At first, 3 districts among 22 districts of Tehran were randomly selected. Then, 3 boy schools from selected districts were randomly chosen. Finally, 400 students were stochastically selected from students of these schools.

\section{2. Research tools}

Research-built questionnaire was used in this study and it was assessed by Likert spectrum. Items related to social capital variable were standardized using questionnaire and also library and documental studies. Of course, number of questions in Mobaraki's questionnaire is more than those used in this study. Because some of his questions were 
related to social discipline and some of them were also omitted from set of questions of this study due to a different statistical population.

The basis of items of current study in relation to delinquency has been associated with study of delinquency by Alikhah (2010 quoted by Shiri). Of course, they have been applied in this study with some changes. Questionnaire used in this study was designed in 7 sections including: 1-social participation (institutional and non-institutional), 2-social confidence (mid-personal), 3-social support (emotional, instrumental or physical, and informational), 4interactions with others (family, friends, neighbors, relatives, and school officials), social solidarity (dependency sense to society), 6-delinquency (opposition to expectations, abnormality, making sensitivity, being anti-value, damaging, making reactions), and 7-trait variables. Each of items was drawn in form of five-option questions.

Except questions related to age and profession of parents and their income that were openly designed, the rest of field questions were in form of closed questions. Social capital contains 46 items including sections one to five of the questionnaire. These sections were characterized with options of "very high", "high", "to some extent", "low", and "very low"/"completely agree", "agree", "disagree", and "completely disagree"/and "always", "very often", "sometimes", "seldom", and "never". Delinquency is in 6 indices of opposition to expectations, abnormality, making sensitivity, being anti-value, damaging, and making reactions including 18 items and they were characterized with options of "always", "very often", "sometimes", "seldom", and "never".

One of the trait variables is socio-economic class that is formed from 4 indices of education (ranked), income (four-option ranked), profession (four-option ranked), and location of residence (three-option nominal). Validity of questions of questionnaire in current study was performed using face validity method.

Face validity or mental validity is based on assessment conducted by researchers and experts that are unanimous on the quality of measurement tool for investigated attributes. And this indicates this point that to what extent designed tool can be as an acceptable indicator of domain of changes. Namely, the questionnaire after design was given to academic professors and graduate students specializing in this matter. And after collecting their opinions as the referee, the final questionnaire was developed. Cronbach's alpha that calculates internal solidarity of measurement tool has been used to calculate the reliability of scale.

A pre-test conducted with a volume of 30 people was applied to measure reliability and alpha amount of measurement tool was obtained. Alpha coefficient for social capital questionnaire and delinquency questionnaire are 0.84 and 0.832 , respectively that are the acceptable amounts indicating high reliability coefficients for questionnaires. Descriptive statistics (percent and abundance) were used in single variable analyses. The regression and Pierson test were applied to investigate the relationship between social capital and delinquency in two variable-analyses. 


\section{3. Findings}

In this study, 400 juvenile students in Tehran have been investigated.

Table 1. Pierson's correlation test results between social capital aspects and delinquency.

\begin{tabular}{|c|c|c|c|}
\hline & & \multicolumn{2}{|c|}{ Delinquency } \\
\hline & & $\begin{array}{c}\text { Correlation } \\
\text { factor }\end{array}$ & $\begin{array}{c}\text { Probability } \\
\text { amount }\end{array}$ \\
\hline \multicolumn{2}{|c|}{ Social capital } & -0.749 & $\mathrm{P}<0.001$ \\
\hline \multirow{5}{*}{ Aspects } & Social participation & -0.641 & $\mathrm{P}<0.001$ \\
\hline & Social confidence & -0.681 & $\mathrm{P}<0.001$ \\
\hline & Social support & -0.721 & $\mathrm{P}<0.001$ \\
\hline & $\begin{array}{c}\text { Interactions with } \\
\text { others }\end{array}$ & -0.609 & $\mathrm{P}<0.001$ \\
\hline & Social solidarity & -0.702 & $\mathrm{P}<0.001$ \\
\hline
\end{tabular}

Regression analysis is one of the methods to predict the response variable using independent variables. Inter method was used to enter these variables and predictor variables were entered into delinquency prediction model in one stage. Table 2 shows coefficients related to research model. Multiple correlation factor or regression coefficient or R indicates the correlation level between amounts of response variable and predicted amounts; also, determinant coefficient shows determination of research model. In other words, the research model determines $61 \%$ of dependent changes and $39 \%$ of dependent variable changes is determined by the other factors. Durbin-Watson Statistics also shows the error rate in estimation of research model.

Table 2 is related to coefficients of research model and Table 3 points to the coefficients of each of predictor variables and their significance.

Table 2. Coefficients related to multivariable regression.

\begin{tabular}{|c|c|c|c|c|}
\hline Model & Multiple R & R square & $\begin{array}{c}\text { Adjusted R } \\
\text { square }\end{array}$ & $\begin{array}{c}\text { Durbin-Watson } \\
\text { statistics }\end{array}$ \\
\hline 1 & 0.772 & 0.610 & 0.610 & 6.791 \\
\hline
\end{tabular}


Table 3. Regression coefficients of independent variables on dependent variables.

\begin{tabular}{|c|c|c|c|c|c|}
\hline \multirow{2}{*}{ Independent variables } & \multicolumn{2}{|c|}{$\begin{array}{c}\text { Un-standardized } \\
\text { regression coefficient }\end{array}$} & $\begin{array}{c}\text { Standardized } \\
\text { regression } \\
\text { coefficient }\end{array}$ & Statistic T & $\begin{array}{c}\text { Probabilit } \\
\text { y amount } \\
\mathrm{P}<0.01\end{array}$ \\
\cline { 2 - 6 } & $\mathrm{B}$ & STD error & BETA & 39.025 & $\mathrm{P}<0.001$ \\
\hline Constant & 89.255 & 2.287 & & -2.096 & $\mathrm{P}<0.001$ \\
\hline Social participation & -0.145 & 0.069 & -0.098 & -3.747 & $\mathrm{P}<0.001$ \\
\hline Social confidence & -0.313 & 0.084 & -0.172 & -6.874 & $\mathrm{P}<0.001$ \\
\hline Social support & -0.657 & 0.096 & -0.452 & -1.840 & 0.212 \\
\hline $\begin{array}{c}\text { Interactions with } \\
\text { others }\end{array}$ & -0.144 & 0.078 & -0.093 & -3.064 & $\mathrm{P}<0.001$ \\
\hline Social solidarity & -0.241 & 0.079 & -0.137 & & \\
\hline
\end{tabular}

Results show that all aspects of social capital except interactions with others are as a predictor of delinquency among juvenile boys in Tehran. In other words, with enhancement of social participation, social confidence, social support, and social solidarity of Tehran juvenile boys, their delinquency probability decreases.

\section{DISCUSSION AND CONCLUSION}

The results of current study showed that all aspects of social capital except interactions with others are as a predictor of delinquency among Tehran juvenile boys. In other words, with enhancement of social participation, social confidence, social support, and social solidarity of Tehran juvenile boys, their delinquency probability decreases. Obtained results about index of "interactions with others" show that based on regression analysis, this variable has lost its own significance by locating beside the other aspects of social capital. Maybe, the reason of this is obscure and multi-dimensional effects of relationship on the delinquency that was investigated as intra- and extra-group relationships of people and their converse effect on the delinquency. And maybe, the reason of this is weakening the social relationships of people in whole society that has resulted in this outcome.

Findings showed that social capital is at high level that most students have gotten a grade higher than average and the accumulation $f$ people in high grades is large. According to the average of 38.78 from domain of changes of this variable from 21 to 81, delinquency level shows that it is in a low level. The results of this study confirm the findings of previous studies. For example, Wright (2001), Salmi and Kivivouri (2006), Ozden Ozbay (2008) know family social capital, the role of individual and structural indices, lack or privation of social capital as an effective variable on deviant behaviors, respectively. Aliverdinia et al. (2007) take into account intimacy among family members and social support in relation to delinquency of boys and parental awareness and membership in social organization in relation to delinquency of girls among components of social capital. Based on theoretical discussions and findings of this research, it can be said that by transition of the society from traditional state to industrial state, social health of people, especially juveniles due to maturation and also encountering a crisis named adolescence crisis will has a more importance. So that health 
subject has been considered by global organizations such as global health organization. Entering to a new society that has varied all structures has affected life of actors mentally. This subject has been argued in our society as a one in transition state from semi-industrial to industrial. Life of people has been varied in the transition process.

These changes not only have affected on life but also on all systems of values and norms of actors. Life in this new structure needs development of all kinds of supports (emotional, financial, informing, and ...), cooperation and membership in social networks. Results of this research show whatsoever people have more social capital in this structure, namely this variable exists as a set of valuable stores such as social, mental, and financial supports, dependency sense, dependence and participation in different aspects of social life for people, social health of people in society will be in a better situation. Amplification of relationship and mental support among family members are done by parents and so they spend more time for family issues and sufficient relationship with each other and with their own children. Of course, should be noted that this support must based on confidence and intimacy, because only in this condition the social capital that its prominent index is the presence of adults at home and argument about social, cultural, scientific, economic and political subjects between children and parents increases and results in decrease in deviant behaviors of family members.

\section{References}

[1] Resheh G. (1988). Social action: an introduction on general sociology, $1^{\text {st }}$ Vol., translated by Zanjanzadeh, $1^{\text {st }}$ publish, Mashhad: Ferdowsi university press.

[2] Rafeapour F. (1999). Anomie or social turbulence: a research in the field of anomie potential in Tehran; $1^{\text {st }}$ publish: Tehran: Soroush.

[3] Salimi A., Davari M. (2007). Sociology of delinquency: set of delinquency studies and social control, $2^{\text {nd }}$ publish, Tehran: research center of university and Hozeh.

[4] Sharifian Sani M. (2001). Social capital: main concepts and theoretical framework, scientific-research journal of social welfare, $1^{\text {st }}$ year, No. 5-18, Tehran Welfare and Rehabilitation Sciences.

[5] Shareapour M. (2001). Erosion of social capital and its outcomes, Iranian institution of sociology letter, 101: 112-113, faculty of social science, Tehran University.

[6] Alikhah F. (2010). Assessment of concepts in social surveys, Vol. 1, Tehran: socialists press.

[7] Aliverdinia et al.; (2008); Social capital of family in delinquency, Women research journal, 6(2), 107-132.

[8] Firouzabadi A., Imani Jajroudi H. (2006). Social capital and socio-economic development in Tehran, scientific-research journal of social welfare, $6^{\text {th }}$ year, No. 23 , Tehran.

[9] Fokoyama F. (2000). End of discipline-social capital and protection of it, translated by Gholam Abbas Tavassoli, Iranian community press.

[10] Golchin M. (2006). Social deviances of juveniles in research mirror, social science letter, No. 28, Autumn 2006.

[11] Mobaraki M. (2005). Investigating the relationship between social capital and crime, M.Sc. thesis in social research, Tehran: Shahid Beheshti University. 
[12] Mousavi et al. (2007). Investigating and assessment of social capital in Iran, $1^{\text {st }}$ Vol., Tehran: University of Welfare and Rehabilitation Sciences.

[13] Molla Mohseni H. (2002). Investigating the relationship between social capital amount and Religiosity among third year high school students in Golestan state (Aliabad and Gonbad), M.Sc. thesis in sociology, Tarbiat Modarres University.

[14] Versley P. (1999). Social discipline in sociology theories, translated by Saeed Moeedfar, set of social sciences, 4(1), Tehran: Tebyan.

( Received 20 October 2014; accepted 29 October 2014 ) 